\author{
Franco Laghi \\ Rafael Fernandez
}

\section{Noninvasive ventilation for weaning in hypoxemic respiratory failure: not ready for prime time}

Received: 25 July 2012

Accepted: 26 July 2012

Published online: 29 August 2012

(C) Copyright jointly held by Springer and ESICM 2012

This editorial refers to the article available at: doi:10.1007/s00134-012-2652-7.

\section{F. Laghi (®)}

Division of Pulmonary and Critical Care Medicine, Edward Hines, Jr. Veterans Affairs Hospital, 111N,

5th Avenue and Roosevelt Road, Hines, IL 60141, USA

e-mail: flaghi@lumc.edu

Tel.: +1-708-2022705

Fax: +1-708-2027907

\section{F. Laghi}

Edward Hines, Jr. Veterans Affairs Hospital, Loyola University

Stritch School of Medicine, Maywood, IL, USA

R. Fernandez

Intensive Care Unit, Hospital Sant Joan de

Deu-Fundacio Althaia, Manresa, Spain
In patients recovering from hypercapnic respiratory failure, intensivists have two choices. They may continue invasive mechanical ventilation until patients can be extubated [5]. In selected cases, intensivists may extubate patients straight away and immediately institute noninvasive mechanical ventilation (NIV) [6, 7]. In contrast, for patients recovering from hypoxemic respiratory failure intensivists have one choice: continue invasive mechanical ventilation until extubation [8]. In the current issue of Intensive Care Medicine, Vaschetto et al. [9] raise the possibility that intensivists may have a second choice: the use of NIV to facilitate discontinuation of invasive mechanical ventilation.

The pilot study by Vaschetto et al. [9] was designed to test the feasibility of using NIV to facilitate weaning in patients with resolving acute hypoxemic respiratory failure. Ten patients were randomized to invasive pressure support (PS, control group) and ten were randomized to noninvasive PS (NIV group). In either case, patients underwent a trial of weaning when positive end expiratory pressure (PEEP) was $8 \mathrm{cmH}_{2} \mathrm{O}$, PS was $10 \mathrm{cmH}_{2} \mathrm{O}$, and partial pressure of oxygen $\left(\mathrm{PaO}_{2}\right)$ to fractional inspiratory oxygen $\left(\mathrm{FiO}_{2}\right)$ ratio was greater than $250 \mathrm{mmHg}$. In the NIV group, weaning trials consisted of $30 \mathrm{~min}$ of patients breathing on their own while solely receiving supplemental $\mathrm{O}_{2}$. In the control group, trials consisted of $30 \mathrm{~min}$ of PS set at $5 \mathrm{cmH}_{2} \mathrm{O}$ plus $5 \mathrm{cmH}_{2} \mathrm{O}$ of PEEP. At the conclusion of the investigation, the two groups were equivalent in terms of arterial blood gas, success of extubation, septic complications, ICU length of stay, and mortality. Twenty-eight days after randomization, the mean (SD) number of days of invasive ventilation were less in the NIV group (10 \pm 9 days) than in the control group ( $20 \pm 8$ days). The number of days of any ventilator support, however, was not different in the two groups.

What should we make of these results? Should we start using NIV in patients recovering from hypoxemic 


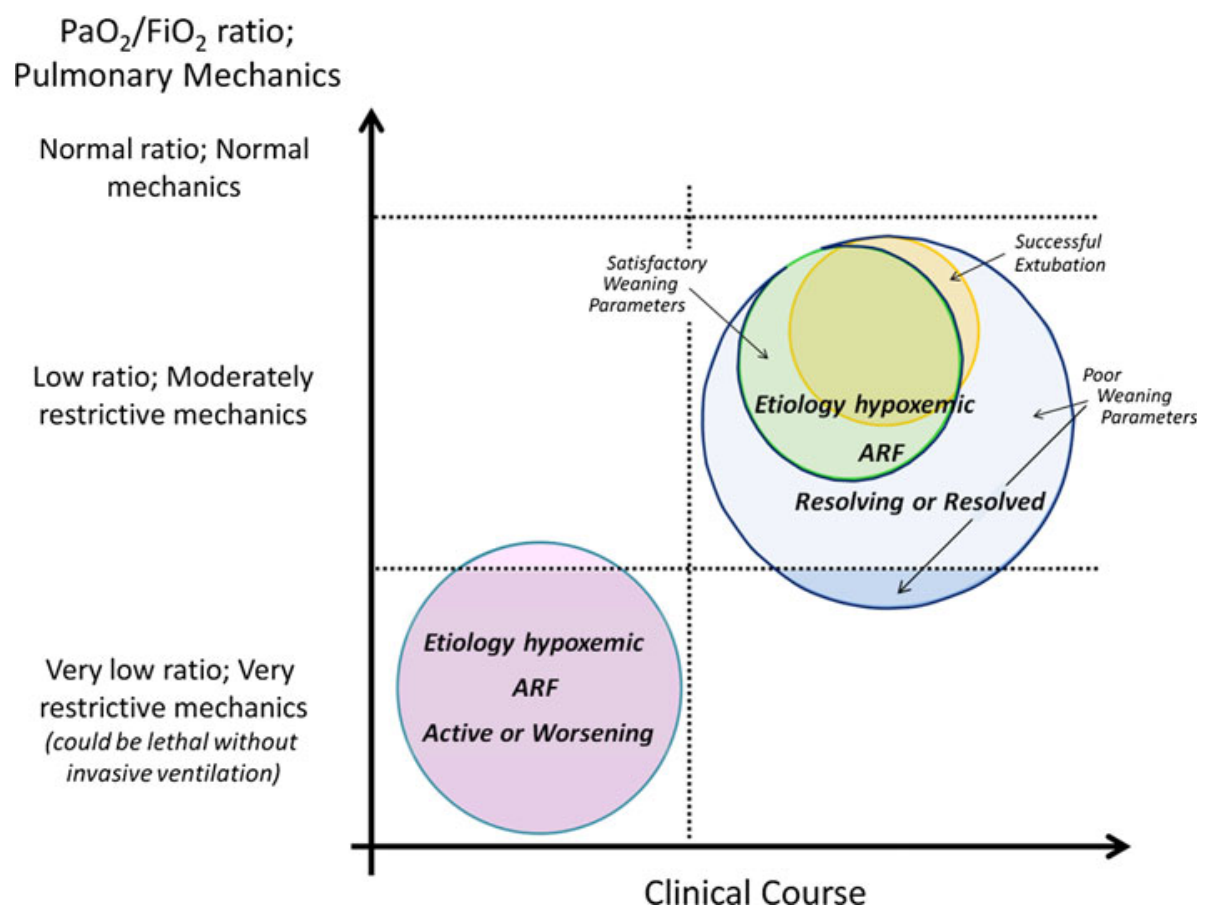

Fig. 1 Schematic representation of the clinical course of patients affected by acute respiratory failure (ARF) receiving invasive mechanical ventilation. Early in the clinical course the etiology responsible for ARF is dynamic (left circle). The partial pressure of oxygen to fractional inspiratory oxygen ratio $\left(\mathrm{PaO}_{2} / \mathrm{FiO}_{2}\right)$ is low and pulmonary mechanics are severely restricted. Most of these patients would die unless invasive mechanical ventilation is

respiratory failure? At this time, the answer is no. First, as recognized by the investigators, this pilot study was not designed to provide outcome data. Second, and more importantly, the heterogeneity in the patients and the different weaning strategies used in the intervention and control groups make it impossible to state whether NIV can facilitate weaning in patients with resolving hypoxemic respiratory failure.

Acute hypoxemic respiratory failure can be caused by a diverse group of diseases [8]. In the current investigation [9], $40 \%$ of patients randomized to NIV (and $50 \%$ of controls) had respiratory failure caused by trauma. It is known that trauma patients can respond favorably to NIV $[8,10]$. In most of the remaining patients, respiratory failure was caused by pneumonia, acute lung injury, or acute respiratory distress syndrome. Respiratory failure caused by any of these three etiologies usually responds poorly to NIV [8]. Unfortunately, Vaschetto et al. [9] do not specify whether the positive results with NIV were driven by their trauma patients or not.

In the Italian study [9], the time for successful discontinuation of invasive and noninvasive ventilation after randomization ranged from zero to 25 days. That is, some patients were ready for unsupported breathing on study enrolment. Including these patients in the study cannot not promptly instituted. Patients who survive the initial insult can experience various degrees of recovery (large right circle). In some of these patients, weaning parameters are satisfactory, and most of them are successfully extubated. Whether noninvasive mechanical ventilation should be used in patients recovering from an episode of ARF who have satisfactory or unsatisfactory weaning parameters remains to be determined

clarify whether NIV may facilitate discontinuation of mechanical ventilation in hypoxemic respiratory failure.

In the investigation by Vaschetto et al. [9], once a target PS was reached, patients in the control group underwent PS weaning. When the same target PS was reached in the NIV group, however, PS was discontinued and patients did breathe on their own while solely receiving supplemental $\mathrm{O}_{2}$. These choices could have prolonged the duration of weaning in the control group for two reasons. First, PS wean can lengthen the weaning period compared to T tube trials [11]. Second, the study was not blinded: investigators were responsible for titration of PS and for starting PS wean as well. This could have introduced a bias towards a more conservative weaning approach in the control group.

Where does all this leave us? We first need to determine whether NIV helps when weaning patients who have satisfactory weaning parameters but fail a trial of unassisted respiration (Fig. 1). If NIV is not inferior to usual care-as the Italian study [9] seems to suggest-we should move to more challenging patients: those with poor weaning parameters and a reasonably high $\mathrm{PaO}_{2} /$ $\mathrm{FiO}_{2}$ ratio (Fig.1). (The pilot data reported by Vaschetto et al. [9] suggest that a ratio of $200-250 \mathrm{mmHg}$ on an $\mathrm{FiO}_{2}$ less than 0.6 could be such a reasonably high ratio.) 
In summary, the investigation by Vaschetto et al. [9] is a challenge to intensivists interested in research on weaning. The economic onus and, more importantly, the human suffering associated with protracted invasive ventilation of patients recovering from an episode of acute hypoxemic respiratory failure demand that we take on this challenge. Our patients deserve no less.

Acknowledgments This research was supported by Veterans Administration Research service.

\section{References}

1. Tobin MJ, Jubran A (2012) Weaning from mechanical ventilation. In: Tobin MJ (ed) Principles and practice of mechanical ventilation, 3rd edn. McGraw-Hill, New York (in press)

2. Jubran A, Lawm G, Kelly J, Duffner LA, Gungor G, Collins EG, Lanuza DM, Hoffman LA, Tobin MJ (2010) Depressive disorders during weaning from prolonged mechanical ventilation. Intensive Care Med 36:828-835

3. Jubran A, Lawm G, Duffner LA, Collins EG, Lanuza DM, Hoffman LA, Tobin MJ (2010) Post-traumatic stress disorder after weaning from prolonged mechanical ventilation. Intensive Care Med 36:2030-2037

4. Tobin MJ, Laghi F, Jubran A (2012) Ventilatory failure, ventilator support and ventilator weaning. In: Dempsey $\mathbf{J}$ (ed) Handbook of physiology: the respiratory system. American Physiological Society, Bethesda (in press)

5. Laghi F (2012) Mechanical ventilation in chronic obstructive pulmonary disease. In: Tobin MJ (ed) Principles and practice of mechanical ventilation, 3rd edn. McGraw-Hill, New York (in press)
6. Nava S, Ambrosino N, Clini E, Prato M, Orlando G, Vitacca M, Brigada P, Fracchia C, Rubini F (1998)

Noninvasive mechanical ventilation in the weaning of patients with respiratory failure due to chronic obstructive pulmonary disease. A randomized, controlled trial. Ann Intern Med 128:721-728

7. Ferrer M, Sellares J, Torres A (2012) NIV in withdrawal from mechanical ventilation. In: Ferrer M, Pelosi P (eds) New developments in mechanical ventilation-European Respiratory Society monographs. Plymouth, UK, pp 191-205

8. Lefebvre J-C, Dimassi S, Brochard L (2012) NIV in hypoxaemic acute respiratory failure. In: Ferrer M, Pelosi $P$ (eds) New developments in mechanical ventilation-European Respiratory Society monographs. Plymouth, UK, pp 65-80
9. Vaschetto R, Turucz E, Dellapiazza F, Guido S, Colombo D, Cammarota G, Della Corte F, Antonelli M, Navalesi P (2012) Noninvasive ventilation after early extubation in patients with hypoxemic acute respiratory failure: a feasibility study. Intensive Care Med. doi:10.1007/s00134-012-2652-7

10. Hernandez G, Fernandez R, LopezReina P, Cuena R, Pedrosa A, Ortiz R, Hiradier P (2010) Noninvasive ventilation reduces intubation in chest trauma-related hypoxemia: a randomized clinical trial. Chest 137:74-80

11. Esteban A, Frutos F, Tobin MJ, Alía I, Solsona JF, Valverdú I, Fernández R, de la Cal MA, Benito S, Tomás R, Spanish Lung Failure Collaborative Group et al (1995) A comparison of four methods of weaning patients from mechanical ventilation. N Engl J Med 332:345-350 